\title{
ORGANIZATION OF AN INTELLECTUAL TECHNOLOGICAL SEARCHING CYCLE TO SUPPORT MAKING DECISIONS DURING A SPACE VEHICLES (SV) REMOTE CONTROL
}

\author{
Bocharov Lev, Sokolov Nikolay, Udaloy Valeriy \\ Mission Control Center and Modeling of Central Scientific and \\ Research Institute of machinebuildin \\ 141070, Pionerskaya str., 4, t. Korolev, Moscow region, Russia.
}

\begin{abstract}
It's explored the designing of intellectual systems problem, which used for acceptance of the exact and operative solutions at control vehicle remote sounding of the Earth. It have example, where the acceptance of operative solution on elimination of contingencies is difficult even very nice experts and require the intellectual searching algorithms. There report outline the basic principles of intellectual systems designing with capability refinement of them in control vehicle. The controlling of Russian-Ukrainian vehicle "Ocean-O" is shown the presence of a large reserve in the operative estimation of flight situations and given the necessary recommendations for designing on control vehicle. By the way, the designing of the intellectual systems is required the special approach to decision on control each other vehicle. For that, it's necessary to take into singularities of onboard vehicle work and the contingencies.
\end{abstract}

Keywords: Intellectual systems, control, knowledge base, acceptance of the solutions.

\section{Introduction}

The most important problem during the remote control SV (space vehicle) is making both of exact and operative decision to have an influence on an onboard systems, especially when an unregular situation is spring up. A wrong decision or a delayed decision may disrupt the mission plan or in certain causes it can be more serious negative consequences.

To make a correct decision the controlling personnel must operatively estimate an onboard systems condition, which include more then 100 telemetry parameters. Also the controlling personnel have to define exact sequence of commanding influence on $\mathrm{SV}$ and make sure, that the commands have been fulfilled during communication session. This problem is sufficient difficult because of rigid temporal limitations.

This work is purpose the questions of the intellectual searching production cycle during communication session making decisions to control SV.

\section{Principles of an intellectual searching production cycle}

There is the general scheme of information searching of the solution to control SV, watch at the fig.1. The input data, which acting at the knowledge base, includes the telemetry information taken from communication session with the SV and information about instrumentation work planed. The knowledge base includes the database, there are: program structure keeping multitude events (S) as objects, attributes and there meaning and rules - it is the set of well-known logic requirements, which setting relations between events (S) and operations (U) as: "If $\mathrm{S}$ then U'. Generally, a rule can contain some events $\mathrm{S}_{i}$. For example, "ARB (angle of rotate battery) parameter of attitude control of the solar battery shows $30^{\circ}$ ", this event includes "ARB parameter" - the attribute, "the attitude system of the solar battery" - the object and " 30 " - the value. The machine of logic conclusions is the logical structure, which establish causal communications of database objects in accordance with purpose of control and getting conclusion rules. 
The output information is the recommendations for decision making as a commanding program on SV.

\section{The singularities of knowledge base formation}

The main content of knowledge base is formed by the experts during the stage of SV preparing for control. However, as the practice shows, there often spring up unpredictable irregular situations during the controlling process, that leads to necessity of getting the new algorithms of finding solutions and knowledge base adaptation during flight of SV.

So, during the controlling process of Russian - Uralian SV "Ocean - O" the regular scheme of engine - flywheel relieving in the pitch channel found oneself ineffective during a magnetic storm arising. The atmospheric density is changed in these cases and there was a large disturbing moment in a pitch channel. There was made kinetic moment of opposite token with the help of engine flywheel rotation for the disturbing moment compensation. However, in connection with bad effecting of magnetic unloading contour work, kinetic moment has a maximum value and then didn't cancel the disturbing moment. This might be lost a both of orientation SV and flight program.

Was offered a new scheme of engine flywheel unloading for orientation of the "Ocean - O". It's basic on periodic corrections of solar batteries (SB) for creation an aerodynamic and a gravitational moments combinations on a pitch channel, which compensatory a disturbing moment. It was required both of really and fast calculation of necessary attitude angle SB value and the programs of their improvement and the command formations and their uplink in communication sessions which duration is not more then 10 minutes. This problem was very difficult even for the very good experts. For its creating there was make an automated work cycle of decision making in multivariate problem. The contains this objects function are:

1.Maintenance of SV orientation;

2.Maintenance of a required power balance;

3.Fulfillments of the given mission plan;
The solution of these problems has a very compromise character. So, the fulfillment of the third problem is making on the necessary energy consumption mode, that possible on some SB values angle rotate. However, for some values these angles is impossible to make the necessary attitude of the SV. Then the first problem must be decided with corrections of the mission plan.

There was entered a complex of new rules for making intellectual information searching in knowledge base permitting to establish logic requirements between the fragments of the solution these problems.

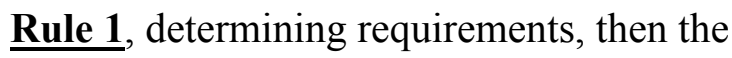
rotation of SB is failed.

$\mathrm{S}_{1}$ - telemetry parameter $\mathrm{VZ} \geq-6 \mathrm{Hms}$;

$\mathrm{S}_{2}-\mathrm{VZ} \geq 6 \mathrm{Hms}$

$\mathrm{S}_{3}-\Delta \mathrm{VZ} \geq 0.8 \mathrm{Hms} /$ orb

If $\left(\mathrm{S}_{1} \wedge \mathrm{S}_{3}\right) \vee\left(\mathrm{S}_{2} \wedge \mathrm{S}_{3}\right)$, then $\Delta \mathrm{UNP}=0$ : the change of $\mathrm{SB}$ position is zero.

Recommendation: the SB rotate is failed. Where: $\mathrm{VZ}$ - value of a kinetic moment in a pitch channel (limiting value $\mathrm{VZ}$ is $\pm 20 \mathrm{Hmc}$ ), $\Delta V Z=\frac{V Z_{n}-V Z_{m}}{n-m}-$ Change of value $\mathrm{VZ}$ in phase from orbit $\mathrm{n}$ to a current orbit $\mathrm{m}$.

$\underline{\text { Rule 2 }}$, determining requirements, then it's necessary to change the position SB.

$\mathrm{S}_{1}-\mathrm{VZ}<-6 \mathrm{Hms}$

$\mathrm{S}_{2}-\mathrm{VZ}>6 \mathrm{Hms}$

$\mathrm{S}_{3}-\Delta \mathrm{VZ}>0.8 \mathrm{Hms}$

If $\mathrm{S}_{1} \vee \mathrm{S}_{2} \vee \mathrm{S}_{3}$, then $\Delta \mathrm{UNP} \neq 0$.

$\underline{\text { Rule 3 }}$, determining rotation parameters SB.

If $\Delta \mathrm{UNP} \neq 0$, then $\Delta \mathrm{UNP}=20 \Delta \mathrm{VZ}$, $\Delta t=\frac{\Delta U N P}{V}$.

Recommendation: the issue of single command (SC) for makes SB a left (right) turn, the issue SC for stopping SB in a time $t$. Where: V - velocity of SB rotation.

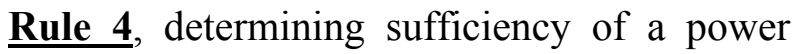
mode of the vehicle for mission plan make. 
If $\mathrm{W}_{\text {req }}(\mathrm{p})>\mathrm{W}_{\text {real }}\left(\mathrm{UNP}, \mathrm{T}_{\Sigma}\right)$, then to change a both of volume of the onboard instruments working and (or) it work time for reduction of vehicle power consumption.

Where: $\mathrm{W}_{\text {req }}(\mathrm{p})$ - the vehicle power consumption require for mission plan $\mathrm{p}$ including onboard instrumentation work $\mathrm{p}_{\mathrm{i}}$ during time $t_{i}$;

$\mathrm{W}_{\text {real }}\left(\mathrm{UNP}, \mathrm{T}_{\Sigma}\right)$ - the real power acting to the vehicle during SB angle rotation, equal UNP during time $T_{\Sigma}$ of onboard instrumentation work.

The values a both of $\mathrm{W}_{\text {req }}$ and $\mathrm{W}_{\text {real }}$ are calculated by the special programs, using the database information.

Rule 5, determining the updating of vehicle mission plan.

If it's necessary to correction of the mission plan, then $p=\sum_{i=1}^{n-1} p_{i} \Delta t_{i}$, to apply the Rule 4 .

However, the database has the priority sequence of the mission plan correction.

Recommendation: the issue of single commands disconnecting the work of the onboard instrumentation excluded of from the mission plan.

There is the functional diagram of a work cycle at the fig. 2 .

\section{Inference}

There is one from the typicalest example of the elimination emergency of solutions intellectual searching adduced above.

Use of the explained approach to organization of an intellectual searching has shown a large reserve in an operative estimation of flight situations. This is allowing to create recommendations for decisionmaking control vehicles on time. It has allowed to experts to supply effective control as this as some another emergency that was in control some vehicle.

References:

[1]Udaloy, V.A., N.M. Ivanov, N.L. Sokolov and V.U. Pazdnikov (2002). Singularities of control Ocean-O in requirements of strong magnetic storms. An international symposium. Space instrumental process engineerings. St.Petersburg.

Input data

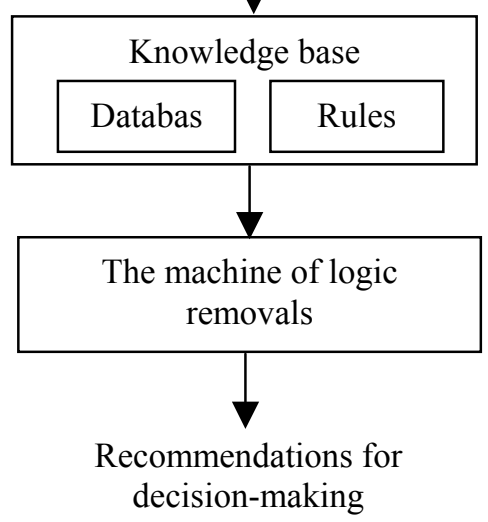

Fig.1.

Scheme of information searching. 
ID

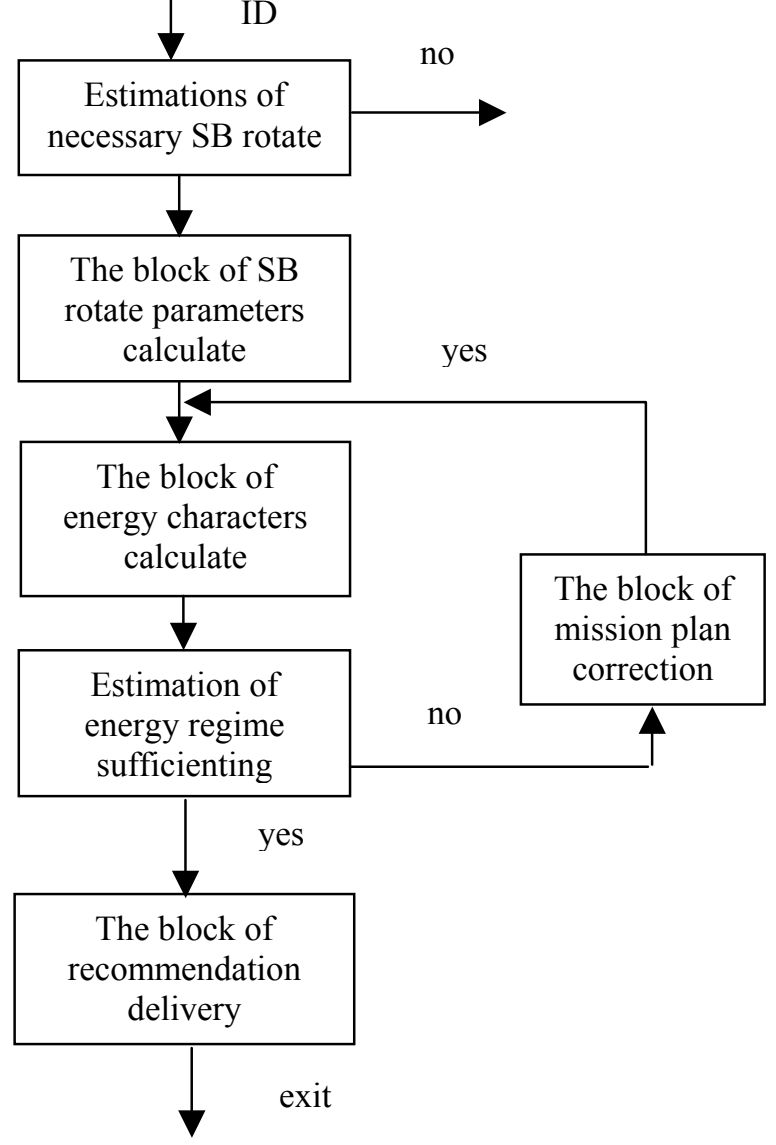

Fig.2.

The functional scheme of the technological cycle. 